\title{
Familial Periodic Ataxia Responsive to Acetazolamide
}

\author{
J.P. Bouchard ${ }^{1}$, C. Roberge ${ }^{1}$, N.M. van Gelder ${ }^{2}$ and A. Barbeau ${ }^{2}$
}

\begin{abstract}
Two cases, a father and son, of recurrent cerebellar ataxia in the same family are reported, suggesting a familial trait for the dysfunction. In the older male the onset of each episode (30-90 min.) was signalled by dysarthria which then progressed towards gait ataxia; the son presented closely similar clinical symptoms. Physical examination and blood chemistry revealed no obvious neurological deficit or biochemical abnormalities, with the exception of I-III and III-IV evoked auditory wave interpeak latencies, which were found markedly abnormal on the left side in the father but not in the son; the EEG of both individuals showed some diffuse, slow wave abnormalities. A low dose of acetazolamide, $250 \mathrm{mg}$ daily, has successfully repressed recurrence of the attacks over the past six months. Temporary withdrawal for 14 days of the carbonic anhydrase inhibitor in the father coincided with two observed ataxic episodes.
\end{abstract}

RÉSUMÉ: Nous rapportons deux cas dans la même famille (père et fils) d'ataxie cérébelleuse récurrente. Chez le père, le début de chaque épisode (30-90 min.) se manifestait par une dysarthrie qui progressait ensuite jusqu'à une ataxie de la marche. Le fils présentait des symptômes semblables. L'examen physique et biochmique ne révéla aucun déficit neurologique évident et aucune anomalie biochimique, mais les latences interpics des ondes du potentiel auditif évoqué I-III et III-IV furent trouvées nettement anormales à gauche chez le père, mais non chez le fils. L'EEG des deux individus a montré quelques anomalies diffuses des ondes lentes. Une faible dose d'acétazolamide, $250 \mathrm{mg}$ par jour, a réussi à supprimer les épisodes ataxiques pour plus de 6 mois. Une période de retrait de cet inhibiteur de l'anhydrase carbonique, d'une durée de 14 jours chez le père, a coincidé avec deux épisodes observés.

Can. J. Neurol. Sci. 1984; 11:550-553

Episodic manifestations of central nervous system dysfunctions are common in clinical neurology (epilepsy, transient ischemic attacks, classical migraine); they often demonstrate a familial preponderance. In these conditions, it is believed that a principal and consistent combination of events triggers a metabolic cascade which not only is responsible for the appearance of the neurological syndrome, but which also limits the process and permits full recovery. Since repeated episodes may eventually lead to permanent CNS damage, and since they also are always socially debilitating in that they restrict job opportunities, it is imperative that treatment should aim at total suppression of the episodes.

A number of rare conditions, most clearly hereditary, temporarily disturb motor functions. The best known are those marked by periodic paralyses (Engel, 1981): periodic ataxia (Parker, 1946) and familial paroxysmal choreoathetosis (Horner and Jackson, 1969). While these conditions have unknown etiologies, other conditions with a similar clinical pattern such as potassium disturbances (paralysis), alcohol or drug intoxications (ataxia), streptococcal infection or pregnancy (chorea) are better known.
This paper describes a new family where both the father and son exhibit periodic ataxia. It also confirms the efficacy of acetazolamide in suppressing the clinical incidents; the drug has previously been reported to be beneficial in four other families (Griggs et al., 1978; Donat and Auger, 1979; Zasorin et al., 1983; Aimard et al., 1983). Finally, we discuss the possible mechanisms by which the carbonic anhydrase (CA) inhibitor, acetazolamide, acts to reduce or prevent the appearance of ataxic episodes.

\section{CASE REPORTS}

Case 1 was born in September 1935 and started to seek help at age 32 (in 1967) for incapaciting episodes of ataxia and dysarthria. These occurred initially once a week and lasted 30 to 90 minutes. On careful inquiry the patient acknowledged that in his teens, he frequently had to stop running because of dizziness and unsteadiness of gait which vanished after a few minutes. These episodes were not accompanied by dysarthria, nausea or other subjective symptoms.

In 1969, he underwent an investigation which showed a decreased labyrinthine response on the right side; the neurological examination was however normal. Attention was then drawn to the possibility of hypoglycemia. Fasting glucose was found to be $69,67,65,55 \mathrm{mg} \%$. 
There was no significant variation during a 24 hour period of fasting. The glucose tolerance test demonstrated a normal elevation ( $30 \mathrm{~min}$.: $185 \mathrm{mg} \%$; $60 \mathrm{~min} .: 212 \mathrm{mg} \%$; $120 \mathrm{~min} .: 126 \mathrm{mg} \%$ ), but a relative hypoglycemia of $39 \mathrm{mg} \%$ at 3 hours was observed without, however, being accompanied by ataxic manifestations. A tolbutamide test was normal.

The subject was admitted to another hospital in April 1981 because the spells had increased in severity and frequency. These spells started with 5-10 minutes of sweating and progressive dysarthria. By that time, he was unable to walk unassisted because of staggering, or to handle objects, and the speech had become incomprehensible. The severe deficits would persist for 30 to 60 minutes, after which a smooth recovery took place over a period of 10 to 15 minutes. There was no relationship between the episodes and fasting, types of meals, stress or exertion. However, the patient reported never to have had an attack when lying down, either at night or during the day. The frequency of the episodes varied from 1 to 3 per week and he claimed to feel "very good" at the end of each episode. He nervertheless lost his job as a truck driver because of these incidents. This social problem was the reason he was re-investigated in April 1982 when he was seen by one of us (JPB).

The patient denied any neurological problem among his parents, grand-parents, uncles, brother (1) and sisters (2) and their offspring. He is the father of non-identical male twins, one of whom proved to suffer similar episodic ataxia (Case II, see below).

Between attacks, physical and neurological examinations were normal. Routine hematologic and electrolyte analyses, renal and liver biochemistry as well as amino acid levels in blood and urine were normal. The only noticeable finding was a slightly elevated total protein level $(57 \mathrm{mg} \%)$ in the cerebrospinal fluid. Brain computed tomography and cerebral angiography revealed no abnormalities.

Electronystagmographic studies disclosed a severe peripheral deficit on the right side, as revealed by caloric tests. Calibration, smooth pursuit, gaze tests and position tests were nervertheless normal. The patient admitted to a direct trauma to the right ear when he was a child, but denied having experienced hypoacousia, tinnitus or vertigo.

Brainstem auditory evoked responses (BAER) were normal on the right side, with a delay in wave $I$ of $1.7 \mathrm{msec}$, and both normal I - III and III - V interval latencies of $2.0 \mathrm{msec}$. There were marked abnormal values on the left side for both I - III $(2.4 \mathrm{msec})$ and III - V $(2.5 \mathrm{msec})$ interpeak latencies.

In June 1982, the patient was placed on acetazolamide, $250 \mathrm{mg}$ once a day for one week, and then twice a day. He was relieved of any ataxic spells, but the dose of acetazolamide then had to be reduced to $250 \mathrm{mg}$ daily because of paresthesia in all four limbs.

Three months later he suffered a typical episode of right renal colic, followed 2 days later by the same on the left side. No calculus was seen on intravenous urography on that occasion, but a slight delay in the excretion through the left ureter was noted. Microscopic hematuria was found. The patient was instructed to increase his water intake. He has not experienced paresthesia or nephritic pain since.

The next ataxic spell took place in January 1983, with a rather sudden onset on a Sunday afternoon, when the patient was resting at home. On inquiry he was not sure if he had taken his pills over that weekend. Acetazolamide was increased to $250 \mathrm{mg}$ twice a day, and over the following months, the patient remained symptom free.

In July 1982, when the patient had been on acetazolamide for one month and still complained of ataxic incidents, he was admitted to hospital; acetazolamide medication was stopped and the patient was placed under observation to witness possible episodes. The only noticeable laboratory findings at that time were an elevated serum chloride level of $112 \mathrm{mEq} / 1$., a decrease of bicarbonates to $18.2 \mathrm{mEq} / 1$., while venous blood $\mathrm{pH}(7.35)$ and serum potassium $(3.7 \mathrm{mEq} / 1$.) were at the lower limits of normal. Partial thromboplastine time tested on two occasions was elevated to 41 seconds (normal 33 seconds), but prothrombin time and coagulation factors (VIII - IX - XI - XII) were normal. Blood sugar, lactate and pyruvate, BUN, transaminases, ceruloplasmin, copper and all other biochemical studies also were normal.

The ataxic attacks were witnessed by one of us. They were reported by the patient to represent "mild" episodes. One happened in late evening on the fourth day (onset $21: 35 \mathrm{hr}$.,duration: $70 \mathrm{~min}$ ) and the other one in the afternoon of the seventh day (onset 16:30 hr., duration: $90 \mathrm{~min}$ ) after cessation of acetazolamide. They were quite similar, starting with dysarthria and then progressing to gait ataxia. On examination at the peak of symptoms there was no nystagmus. The speech was slurred, slightly scanned; walking was possible with increased base and loss of balance mainly occurred when turning. Adiadocokinesis and dysmetria were found to be mild and mere pronounced on the left side during the first observed episodes, moderate in intensity and worse on the right side during the second episode. Tandem gait was impossible but the Romberg test was negative. Muscle strength appeared entirely normal, as were deep and cutaneous sensations, tendon reflexes and plantar response. On both occasions moderate diaphoresis to face, hands and feet was noted, but not to truncal, axillar nor inguinal regions.

Biochemical parameters were normal during these episodes with respect to venous and arterial $\mathrm{pH}$, electrolytes, blood sugar, calcium, magnesium, phosphorus, transaminases, and amino acids. Pyruvate and lactate could not be determined during the attacks.

Three electroencephalograms (EEG) were performed during the acetazolamide-free period, one of them shortly before the end of an attack. The EEGs showed mild paroxysmal abnormalities, consisting of a few short bursts of medium voltage generalized slow activity ( 3.5 to $6 \mathrm{~Hz}$ ) over both hemispheres, mainly over anterior and mid-temporal areas, with a slight preponderance on the left side. Hyperventilation slightly increased the abnormalities. Background activity at $10 \mathrm{~Hz}$ was normal, as well as response to intermittent phototic stimulation. During the recordings, the patient was not drowsy, and no epileptic discharges were noted.

The patient has now been asymptomatic for the last 6 months, on acetazolamide. During that period, BAER on the left side returned to normal. The initial delay before peak I remained unchanged on the right side.

Case 2, the son, is a non-identical twin born in 1962. He has "never" been sick and is active and practices weight-lifting. When seen in March 1983, he acknowledged a four year history of dizzy spells. At the beginning he felt just dizzy for a few minutes, apparently without any relationship to activity. These episodes occured about once every other month. When he came to us, he complained that the frequency (twice a month) and intensity of the episodes were increasing. These were still short in duration (5 to 15 minutes) and consisted of either staggering gait, or dysarthria, or both in the following sequence: first staggering and then slurred speech. He sat down for a while and then resumed former activities. He never had nausea, vertigo, diplopia or any other symptoms.

Physical and neurological examination were normal. There was no nystagmus. As a result of weight lifting he had a large muscle bulk. Blood studies for hemogram, BUN, electrolytes, proteins, glucose transaminases were all normal. EEG was within normal limits. A few short bursts of slow generalized activity were seen during hyperventilation only. He was put on acetazolamide $250 \mathrm{mg}$ in the morning and since has been completely free of attacks.

\section{DISCUSSION}

Our cases are quite similar to those reported by Griggs et al. (1978) and Zasorin et al. (1983), both with reference to their episodic manifestations and to their favorable response to acetazolamide. Donat and Auger (1979) successfully treated a mother and her son with acetazolamide, although a somewhat different clinical picture was manifested. They then reviewed the literature to find records of seven other families with periodic ataxia. As early as 1946, Parker coined the expression " periodic ataxia" to described episodic symptoms in multiple sclerosis among four families. He has also underlined the relationship between periodic ataxia in two offsprings of a parent with progressive spino-cerebellar degeneration. The three other families encompassed a large number of individuals over several generations (White, 1962; Farmer and Mustian, 1963; Hill and Sherman, 1968). Persistant mild ataxia and nystagmus were present in more than half of the cases. The duration of the episodes varied from minutes (Parker, 1946) to weeks (Hill and Sherman, 1968), but the overall clinical expression (age at onset of attacks, rapid progression to gait ataxia, dysarthria, variable 
upper limbs dysmetria, with or without nystagmus) is quite stereotyped in a given family. An interesting association of ataxic episodes in association with myokymia has been reported by van Duke (1975) in a large kinship.

Hill and Dysart (1975) have discussed the susceptibility of cerebellum in young children to various infections or toxic influences. In the same book, Salam (1975) in a chapter on metabolic ataxias, reviewed the amino acidopathies that are essentially diseases of chilhood and which account for most recurrent attacks of episodic ataxia seen at this age. A number of specific enzyme deficiencies have been described in these cases. Often the disorder is so severe that mental retardation becomes the prominent feature.

This is not the case in the syndrome reported as "familial periodic ataxia". Although the ataxic episodes start in infancy or childhood in some of the large kinships (White, 1962; Hill and Sherman, 1968; Griggs et al., 1978), in these cases no abnormalities were found in the amino acid content of blood or urine, nor in cases beginning in the teens or later in life. In all investigated cases including our own, no biochemical leads have been found.

Electrophysiological studies have also yielded little information on the nature and localisation of the process. Electromyography and nerve conduction studies were normal in all reported instances. EEGs were normal in most cases, and showed only mild generalized slowing (Hill and Sherman, 1968) with dysrhythmia (Donat and Auger, 1979) in some. Bursts of slow and sharp activity were demonstrated in two cases by Zasorin et al. (1983). Although less marked, the bursts of slow activity seen in three different recordings of the father are likely of the same nature. These are reminiscent of the bursts encountrered in more than $50 \%$ of the patients with autosomal recessive spastic ataxia of Charlevoix-Saguenay (Bouchard et al., 1979) or much less often, in Friedreich's ataxia (Rémillard et al., 1976; Bouchard et al., 1979). These episodic EEG manifestations are believed to originate from involvement of diencephalic or brain stem structures in spastic and Friedreich's ataxia. In our patient, the bursts were not changed in quantity and quality when recording was done during the last minutes of an ataxic spell. Although certainly not specific, these abnormalities point to some similarity between progressive and periodic ataxias.

Of more interest are the brain stem auditory evoked responses (BAER) in the few reported cases with familial periodic ataxia. They were normal in one case (Donat and Auger, 1979) while Zasorin et al. (1983) described asymmetric but bilateral prolonged I - V interpeak latencies in another case. They stated that the BAER had reverted to normal two weeks later, after "steroids were given". Asymmetric prolonged I - V interpeak latencies were seen in the father before acetazolamide therapy and the BAER was normal after 18 months of treatment.

A number of BAER and other evoked potential studies in various inherited ataxias have recently been published (SatyaMurti et al., 1980; Pedersen and Trojaborg, 1981; Taylor et al., 1982; Nuwer et al., 1983; Jabbari et al., 1983). To summarize the data, one may state that BAER are often normal in young Friedreich's ataxia (FA) patients, and deteriorate with time and clinical status. This is not true for all patients and Nuwer (1983) reported normal results in all their FA cases. The same authors studied two cases of combined cerebral-cerebellar-cortical atrophy with intermittent ataxia and impairment of pyruvate dehydrogenase: one had normal responses and the other no response at all.
Asymmetric changes of the BAER have seldom been noted in progressive ataxias. In Zasorin's case (Zasorin et al., 1983) asymmetric and temporary abnormalities were found. In our older patient, unilateral delay of both I - III and III - V interpeak latencies were present during a non ataxic period, indicating a diffuse brain stem dysfunction even when the subject was asymptomatic. The role of acetazolamide in returning the BAER to normal is unknown.

It is now believed that periodic ataxia is likely caused by a partial defect in enzymes of the pyruvate dehydrogenase (PDH) complex, which leads to the accumulation of pyruvate, lactate and alanine (Zasorin et al., 1983). Other enzymatic defects, as reviewed by Salam (1975), might represent cofactor deficiencies that could influence the rate of pyruvate oxidation and produce this syndrome-complex.

Reynold and Blass (1976) suggested that pyruvate oxidation was lower in the anterior cerebellar vermis, compared to other parts of the brain. They postulated that a defect in $\mathrm{PDH}$, too mild to impair carbohydrate metabolism elsewhere, could selectively cause dysfunction at this level. Furthermore it is known that decreased PDH activity reduces the synthesis of acetylcholine (Gibson et al., 1975). On this basis, physostigmine (Kark et al., 1977) and lecithin (Barbeau, 1978) were given to chronically ataxic patients, with some success. To our knowledge such a therapy has not been evaluated in periodic ataxia.

Acetazolamide in periodic ataxia was first used because the syndrome had been misdiagnosed as periodic paralysis. This carbonic anhydrase inhibitor was first used in familial hyperkalemic periodic paralysis (MacArdle, 1962) because of its kaliuretic effect. Acetazolamide was found efficient as well in the prophylaxis of hypokalemic periodic paralysis (Resnick et al., 1968). One still wonders about its exact role in periodic paralysis. An unexpected dissociation of glucose and potassium arterial-venous differences by acetazolamide has just been reported (Riggs et al., 1984). Acetazolamide is well known for its anticonvulsive action (Woodbury, 1980) but it is also effective on myotonia (Griggs et al., 1978), as are other anticonvulsive agents such as taurine (Durelli et al., 1983) and phenytoin.

The fundamental role of $\mathrm{CA}$ in glial cell metabolism has been known for many years (Maren, 1967; Woodbury, 1980). By reversibly catalyzing the hydration of $\mathrm{CO}$ to carbonic acid which then spontaneously dissociates into $\mathrm{HCO}-+\mathrm{H}$, the enzyme closely regulates glial $\mathrm{pH}$ and the intracellular ionic bicarbonate concentration. The bicarbonate ion undergoes exchange with extracellular $\mathrm{Cl}$, a process which is accompanied by influx of $\mathrm{Na}$ and water. Under circumstances where glia have a problem in ejecting water, carbonic anhydrase activity may therefore promote glial swelling, with pathological consequences. Glutamine synthesis within the CNS is considered to be the exclusive domain of glia and release of glutamine has been proposed to represent the primary mechanism by which glia redress the water balance following CA mediated water influx (van Gelder, 1983). A familial trait or an acquired insufficiency in the complex metabolic cycle leading to glutamine synthesis and release, during stimulated CA activity, may cause periodic swelling of the satelite cells. In at least one form of familial cerebellar ataxia, an abnormality in glutamic acid metabolism has been reported; the amino acid represents the principal substrate for glutamine synthesis.

Kjallquist et al. (1969) noted a reduction in brain lactate and pyruvate with acetazolamide, but it is not known if this happens 
by inhibition of $\mathrm{CA}$ or by some effect on the enzymes concerned with pyruvate metabolism (Evans et al., 1978). That metabolism is however very sensitive to cellular $\mathrm{pH}$ changes. The same point can be made about acetazolamide in the treatment of periodic ataxia.

Although generally well tolerated, acetazolamide may cause a number of side-effects. Paresthesias and renal calculi are common in the first few weeks of treatment as in case one in the present report. Paresthesias faded out with reduction of dosage and cristalluria disappeared with better water intake. If more serious side effects would arise, we would like to suggest that a substance with some analogous effects such as taurine could be tried. Whether or not physostigmine might be efficient in stopping or preventing the spells in periodic ataxia has not been evaluated and we plan to answer this question in the future.

\section{ACKNOWLEDGEMENTS}

These studies were supported by grants from " $L$ 'Association Canadienne de l'Ataxie de Friedreich". We wish to thank Dr. C. Richards for her advice and Mrs. A. LaBrecque for her assistance.

\section{REFERENCES}

Aimard G, Vighetto A, Trillet M, Ventre JJ, Devic M (1983) Ataxie paroxystique familiale sensible à l'acétazolamide. Rev Neurol (Paris) 139: $251-257$.

Barbeau A (1978) Emerging treatments. Replacement therapy with choline or lecithin in neurological diseases. Can J Neurol Sci 5: 157-160.

Bouchard RW, Bouchard JP, Bouchard R, Barbeau, A (1979) Electroencephalographic findings in Friedreich's ataxia and autosomal recessive spastic ataxia of Charlevoix-Saguenay. Can J Neurol Sci 6: 191-194.

Donat JR, Auger R (1979) Familial periodic ataxia. Arch Neurol 36: 568-569.

Durelli L, Mutani R, Fassio F (1983) The treatment of myotonia: evaluation of chronic oral taurine therapy. Neurology 33: 595-603.

Engel AG (1981) The periodic paralyses. In: Walton (ed.) Disorders of voluntary muscle (4th edition), London, Churchill-Livingstone, pp 665-670.

Evans OB, Kilroy AW, Fenichel GM (1978) Acetazolamide in the treatment of pyruvate dysmetabolism syndromes. Arch Neurol 35: 302-305.

Farmer TW, Mustian VM (1963) Vestibulocerebellar ataxia. A newly defined hereditary syndrome with periodic manifestations. Arch Neurol 8: 21-30.

Gibson GE, Jope R, Blass JP(1975) Decreased synthesis of acetylcholine accompanying impaired oxydation of pyruvic acid in rat brain minces. Biochem J 148: 13-23.

Griggs RC, Moxley RT, Riggs JE, Engel WK (1978) Effects of acetazolamide on myotonia. Ann Neurol 3: 531-537.

Griggs RC, Moxley RT, Lafranche RA, McQuillen J (1978) Hereditary paroxysmal ataxia: response to acetazolamide. Neurology 28 : 1259-1264.
Hill W, Sherman H (1968) Acute intermittent familial cerebellar ataxia. Arch Neurol 18: 350-357.

Hill W, Dysart D (1975) Hereditary periodic ataxias. In: Vinken PJ, Bruyn, GW, eds. Handbook of Clinical Neurology, vol 21, Amsterdam, North Holland Publ Co, pp 563-571 (ch 31).

Horner FA, Jackson LC (1969) Familial paroxysmal choreoathetosis. In: Barbeau A, Brunette JR, eds. Progress in Neuro-Genetics, vol 1, Amsterdam, Excerpta Medica, pp 745-757.

Jabbari B, Schwartz DM, Macneil DM, Coker SV (1983) Early abnormalities of brain stem auditory evoked potential in Friedreich's ataxia: evidence of primary brain stem dysfunction. Neurology 33: 1071-1074.

Kark RAP, Blass JP, Spence MA (1977) Physostigmine in familial ataxias. Neurology 27: 7-72.

Kjallquist A, Nardini M, Siesjo BK (1969) The effect of acetazolamide upon tissue concentrations of bicarbonate, lactate and pyruvate in the rat brain. Acta Physiol Scand 77: 241-251.

Maren TH (1967) Carbonic anhydrase: chemistry, physiology and inhibition. Physiol Rev 47: 595-781.

Nuwer MR, Perlman SL, Packwood JW, Kark RAP (1983) Evoked potential abnormalities in the various inherited ataxias. Ann Neurol 13: 20-27.

Parker HL (1946) Periodic ataxia. In: Hewlett RM et al, eds. Collected papers of the Mayo Clinic. Philadelphia, WB Saunders Co, 38: 642-645.

Pedersen L, Trojaborg W (1981) Visual, auditory and somatosensory pathway involvement in hereditary cerebellar ataxia, Friedreich's ataxia and familial spastic paraplegia. Electroencephalogr Clin Neurophysiol 52: 283-297.

Remillard G, Andermann F, Blitzer L, Andermann E (1976) Electroencephalographic findings in Friedreich's ataxia. Can J Neurol Sci 3: 309-312.

Resnick JS, Engel WK, Griggs RC, Stam AC (1968) Acetazolamide prophylaxis in hypokalemic periodic paralysis. N Engl J Med 278: 582-586.

Riggs JE, Griggs RC, Moxley RT (1984) Dissociation of glucose and potassium arterial-venous differences across the forearm by acetazolamide. Arch Neurol 41: 35-38.

Salam M (1975) Metabolic ataxias. In: Vinken PJ, and Bruyn GW eds. Handbook of Clinical Neurology, Amsterdam, North Holland Pub! Co, vol 21, pp 573-585 (ch 32).

Satya-Murti S, Cacace A, Hanson P (1980) Auditory dysfunction in Friedreich's ataxia: result of spiral ganglion degeneration. Neurology 30: 1047-1053.

Taylor MJ, McManamin JB, Andermann E, Watters GV (1982) Electrophysiological investigation of the auditory system in Friedreich's ataxia. Can J Neurol Sci 9: 131-135.

van Dyke DH, Griggs RC, Murphy MJ, Goldstein MN (1975) Hereditary myokymia and periodic ataxia. J Neurol Sci 25: 109-118.

van Gelder, NM (1983) Metabolic interactions between neurons and astroglia: Glutamine synthetase, carbonic anhydrase and water balance. In: Jasper HH, van Gelder NM, eds. Basic Mechanisms of neuronal excitability, New York, AR Liss pp 5-29.

White JC (1969) Familial periodic nystagmus, vertigo and ataxia. Arch Neurol 20: 276-280.

Woodbury DM (1980) Carbonic anhydrase inhibitors. In: Glaser GH. Penry JK, Woodbury DM, eds. Antiepileptic drugs: mechanisms of action, New York, Raven Press, pp 617-633.

Zasorin NL, Baloh RW, Myers LB (1983) Acetazolamide-responsive episodic ataxia syndrome. Neurology 33: 1212-1214. 